\title{
Management of Hemophilia Patient
}

\section{${ }^{1}$ Mamtha S Nanjappa, ${ }^{2}$ Priyanka R Bhoboo, ${ }^{3}$ Kishore Felix, ${ }^{4}$ Narahari Ranganatha}

\begin{abstract}
Hemophilia comprises a group of hereditary bleeding disorders caused due to the deficiency of one or more clotting factors. It is classified as hemophilia A, B and C which occur due to deficiency of factor VIII, IX or X respectively. Hemophilia A is an $\mathrm{X}$-linked recessive hereditary disorder and most common of the three. It accounts for 80 to $85 \%$ of bleeding disorder. It is of paramount importance to know this medical condition to provide dental treatment and to prevent undesirable events. The aim of this article is to report a case of hemophilia A, who was diagnosed postextraction with review of dental management of hemophilic patients.
\end{abstract}

Keywords: Dental extractions, Hemophilia, Management.

How to cite this article: Nanjappa MS, Bhoboo PR, Felix K, Ranganatha N. Management of Hemophilia Patient. J Health Sci Res 2017;8(2):72-76.

\section{Source of support: Nil}

\section{Conflict of interest: None}

\section{INTRODUCTION}

Hemophilia is an inherited blood clotting disorder, clinically it presents as a bleeding tendency. ${ }^{1}$ It is a challenge for dental practitioners to manage such a situation. The mechanism of blood clotting involves series of events. When a blood vessel is injured, platelets collect over the injured area and form a temporary plug to prevent further bleeding. However, this temporary plug is too disorganized to serve for a long term, so a series of chemical events occur, resulting in the formation of a more reliable plug. The final plug involves tightly woven fibers of a material called fibrin. ${ }^{2}$ The production of fibrin requires the interaction of several chemicals, in particular a series of 13 proteins called clotting factors. In hemophilia the clotting factors VIII, IX or X are deficient in quantity, absent or improperly formed. Since the clotting cascade uses amplification to rapidly plug up a bleeding area, absence or inactivity of just one clotting factor can greatly increase bleeding time., ${ }^{2,3}$

\footnotetext{
${ }^{1}$ Professor and Head, ${ }^{2,3}$ Postgraduate Student, ${ }^{4}$ Senior Lecturer

${ }^{1-4}$ Department of Oral and Maxillofacial Surgery, RajaRajeswari Dental College \& Hospital, Bengaluru, Karnataka, India

Corresponding Author: Mamtha S Nanjappa, Professor and Head, Department of Oral and Maxillofacial Surgery, RajaRajeswari Dental College \& Hospital, Bengaluru, Karnataka, India, Phone: +919880194412, e-mail: drmamathans@yahoo.com
}

Hemophilia A is the deficiency of factor VIII ${ }^{1,4}$ (antihemophilic factor), and hemophilia B also called Christmas disease is the deficiency of factor $\mathrm{IX}^{1,4,5}$ (Christmas factor). Hemophilia C involving factor $\mathrm{XI}^{1,5,6}$ (plasma thromboplastin antecedent) is very rare but much milder than hemophilia A or B. The plasma concentration of factors between 50 and $100 \mathrm{IU} / \mathrm{dL}$ is considered as normal. The plasma concentration of factors between 6 and $40 \mathrm{IU} / \mathrm{dL}$ is mild, range between 2 and $4 \mathrm{IU} / \mathrm{dL}$ is moderate and concentration below $1 \mathrm{IU} / \mathrm{dL}$ the manifestation of the disease are severe. ${ }^{3,7}$ In hemophilia, laboratory investigations reveal isolated prolongation of activated partial thromboplastin time (APTT), although the bleeding time, prothrombin time (PT), and thrombin time are usually normal. ${ }^{8}$

Hemophilia is further classified on the basis of concentration of factors as mild when the concentration is 0.05 to $0.35 \mathrm{IU} / \mathrm{mL}$ or 5 to $35 \%$, these cases present with late onset of bleeding following trauma or surgery or dental extractions. ${ }^{5}$ It is considered moderate when factor concentration is 0.01 to $0.05 \mathrm{IU} / \mathrm{mL}$ or 1 to $5 \%$, and it presents as bleeding into joints or muscles with minor trauma and excessive bleeding with surgery. It is considered to be severe when concentration is $<0.01 \mathrm{IU} / \mathrm{mL}$ or $<1 \%$. In these cases spontaneous bleeding occurs in the joints, muscles, brain and there is increased bleeding in the event of trauma or surgery. ${ }^{9}$

\section{CASE REPORT}

A 20-year-old male patient presented to the Department of Oral and Maxillofacial Surgery, RajaRajeswari Dental College \& Hospital, Bengaluru, Karnataka, India, with a chief complaint of uncontrolled bleeding since 9 days from the site of tooth removal. The tooth was extracted in a private clinic as a part of his orthodontic treatment 10 days earlier.

A detailed case history was taken in which patient gave history of several episodes of delayed wound healing in his childhood and also history of jaundice 1 year back. Patient did not report any other medical condition and was not on any kind of medication. His past dental history revealed that patient had started his orthodontic treatment 1 month ago. As a part of treatment plan, all four 1st premolars were planned to be extracted. Accordingly, the upper right 1st premolar was extracted 10 days back in a private clinic. On the $3 \mathrm{rd}$ postoperative day, he noticed bleeding from the extraction site. He reported back to the 
private clinic for the same where the clinician controlled the bleeding with pressure pack followed by suturing. There was another episode of slow and continuous bleeding from the extraction socket after 2 days which continued upto 9 days. The patient was referred to Rajarajeswari Dental College and Hospital, Bangalore, Karnataka, India, for further evaluation and management.

General physical examination revealed signs of pallor, pitting edema in the right feet and spoon shaped nails. On oral examination, we observed a huge clot, bluishblack in color measuring $3 \times 3 \mathrm{~cm}$, loosely hanging from the extraction socket in relation to 14 . The clot was friable, which bled instantly on slight touch (Fig. 1).

A differential diagnosis like thrombocytopenia, Von Willebrand disease, platelet dysfunction, liver disease, dysfibrinogenemia was given. To evaluate the bleeding abnormality various investigations were done like complete hemogram $(\mathrm{CBC})$, prothrombin time (PT), activated partial thromboplastin time APTT and international normalized ratio (INR).

Intraoral periapical radiographs showed complete removal of the tooth 14 . The site (socket) was then debrided and explored to find out the source of bleeding: whether it was from soft tissue or bone. Bleeding was found to be from bone. The site was then packed with a local hemostatic agent (Abgel) followed by figure of eight suturing, which was done using silk sutures (Fig. 2). The patient was also prescribed Tab styptovit $500 \mathrm{mg}$ TID. The patient was then admitted to the hospital for further evaluation where he was prescribed Tab Limcee $500 \mathrm{mg}$ and Injection VCEF forte (Ceftriaxone $1000 \mathrm{mg}$, Sulbactam $500 \mathrm{mg}$ ).

The routine blood results suggested that hemoglobin, bleeding time, clotting time, red blood cells, white blood cells, and platelet count were within the normal range. The PT screens the extrinsic limb and common

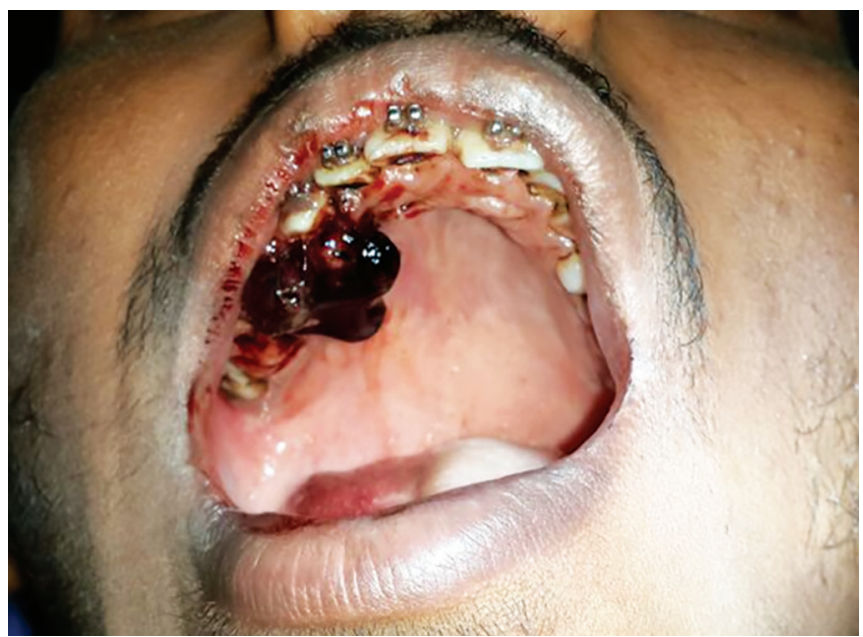

Fig. 1: Preoperative intraoral view showing a huge clot at the extraction site of 14 coagulation pathway. There was slight increase in prothrombin time, i.e. $17.4 \mathrm{sec}$ which suggested that patient was either on warfarin anticoagulant therapy, vitamin K deficiency or deficiency of factors - V, VII, X, prothrombin/fibrinogen. International normalized ratio is a measure of extrinsic pathway of coagulation cascade. The INR was raised to 1.45, it was suggestive of warfarin use, underlying liver damage or vitamin $\mathrm{K}$ deficiency. Partial thromboplastin time (PTT) screens the intrinsic pathway and common coagulation pathway. Activated partial thromboplastin time was 83.1, it was suggestive of hemophilia. If values of both test, i.e., PT and PTT are prolonged; it implies deficiency of factor II, V, X, Vitamin K deficiency, liver disease can be suspected.

After 48 hours following admission of the patient to the hospital, he reported of mild bleeding from the site. On exploring the site, bleeding was found to be from the palatal mucosa. Bleeding was arrested with pressure pack and 1 dose of tranexamic acid injection into the site, following which he was advised to undergo factor VIII and IX assay. The results showed that the factor VIII value was decreased to $38 \%$ and factor IX was decreased to $46 \%$, suggestive of mild hemophilia.

The patient was discharged on 4th day and socket showed signs of healing. Two weeks follow-up was uneventful. The patient was instructed about the condition like avoiding injury and usage and role of tranexamic acid in controlling bleeding.

\section{DISCUSSION}

Hemophilia predisposes patient to high risk of secondary bleeding following oral surgery. Consultation with a hematologist is required prior to dental surgery. ${ }^{6}$ The World Federation of Hemophilia advises the use of factor concentrates to cryoprecipitate or fresh

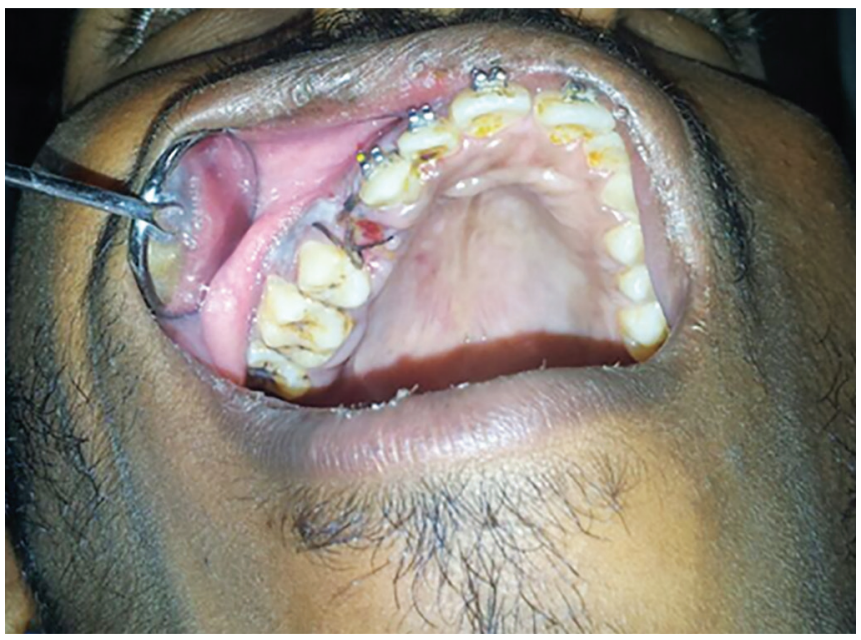

Fig. 2: Postoperative intraoral view showing sutured 14 socket site 
frozen plasma for replacement therapy in patients with hemophilia. $^{7}$

One unit of infused recombinant factor VIII $/ \mathrm{kg}$ of body weight should lead to a rise of plasma factor VIII level of approximately $2 \%$ in patients with hemophilia A and in absence of an inhibitor. The half life of factor VIII is 8 to 12 hours. $^{7}$ The following formulas can be applied for calculating the factor dose:

Dosage (units) $=$ body weight $(\mathrm{kg}) \times$ desired factor VIII rise (IU/dL or \% of normal) $\times 0.5$

and

Dosage (units) $=$ body weight $(\mathrm{kg}) \times$ desired factor IX rise (IU/dL or \% of normal) ${ }^{7}$

One unit of plasma-derived factor IX concentrate $/ \mathrm{kg}$ of body weight infusion will raise factor IX activity by $1 \%$ approximately in absence of an inhibitor. ${ }^{8}$ The recombinant factor IX infusion raises plasma factor IX level by $0.8 \%$ in adult and $0.7 \%$ in children. ${ }^{9}$ The half-life of factor IX is approximately 18 to 24 hours. ${ }^{10}$

The conventional replacement therapy is not effective in patients with antibodies to factor VIII and IX. A number of genetic and immunologic factors are responsible in inhibitor development. ${ }^{11-16}$ This is observed in 8 to $20 \%$ of the patients with severe hemophilia A and 2.5 to $16 \%$ in hemophilia B. ${ }^{11}$ However, an activated prothrombin complex concentrate or a recombinant activated factor VIII concentrate can be used in these patients. ${ }^{17}$

Factor replacement therapy carries a risk of transmission of viruses or new pathogens and may lead to develop inhibitors. Therefore decreasing the number of replacement therapy is beneficial. A single dose of $0.3 \mu \mathrm{g} / \mathrm{kg}$ of factor VIII of body weight, preoperatively can increase the factor VIII level three to six fold in good responders. ${ }^{18,19}$ It is much less expensive than coagulation factor concentrates. The advantage is that, there is no risk of transmission of infections or immunization. It is necessary to test patient's response prior to surgery.

\section{Dental Extractions}

In patients with inherited bleeding disorders, careful treatment planning is essential. In case of multiple extractions it is advisable to perform them one at a time.

Because of the risk of hematoma formation, infiltration and intraligamentary anesthesia with a vasoconstrictor are often alternatives to nerve block. ${ }^{20}$ Procedures can be carried out under sedation so as to reduce nerve block and in whom extensive treatment is required. A dental impression should be taken prior to the extraction and cast in the laboratory. The tooth being extracted is removed from the model and a soft vacuum-formed splint is constructed to cover the socket completely. Rubber band extractions should be the preferred technique. Extraction should be done as atraumatically as possible and the socket should be packed with local hemostatic agent like fibrin glue or resorbable gelatin sponge coated with thrombin powder. ${ }^{21}$ If fibrin glue is not available, the socket may be packed with a resorbable gelatin sponge (Gelfoam $\left.{ }^{\circledR}\right)$ rolled in thrombin powder (Thrombostat ${ }^{\circledR}$ ). ${ }^{22}$ It may be possible to substitute oxidized cellulose (Surgicel ${ }^{\circledR}$ ) for the gelatin sponge, as they work in a similar manner. Absorbable sutures can also be used to avoid bleeding which occurs during suture removal. A vaccum formed splint fabricated prior to extraction can be placed in the oral cavity for 48 hours. ${ }^{23}$ The patient should be observed for bleeding upto 24 hours and should be instructed not to rinse the mouth following the extraction. The patient should be instructed not to wash the mouth vigorously. Soft diet is advised for 7 days. Antifibrinolytic agents like epsilon-aminocaproic acid and tranexamic acid ${ }^{24}$ can be used postoperatively to protect the clot. ${ }^{20}$ Tranexamic acid $10 \%$ solution has been used as a mouthwash and has shown to reduce bleeding. ${ }^{25}$ The splint is removed after 48 hours and the socket is checked again for clot formation. If necessary, splint can be continued to be worn for the next 24 hours. Tranexamic acid either orally or systemically ( $1 \mathrm{~g}$ or $15 \mathrm{mg} / \mathrm{kg}$ every 8 hours) is started, day before the procedure or before extraction and continued for 7 days. ${ }^{10}$ The prophylactic use of antibiotics is beneficial in decreasing the secondary infection following extraction. Monitor the blood pressure. Benzodiazepines can be used to reduce anxiety. Pain is reduced by nonsteroidal anti-inflammatory drugs, which affect activity of platelets and therefore should be avoided. ${ }^{20}$ The drug of choice is paracetamol. ${ }^{26}$

Local hemostatic measures like pressure pack, sutures, ${ }^{23}$ collagen, oxycellulose, ${ }^{27}$ gelatin, fibrin glue, and cyanoacrylate $^{28}$ are necessary following dental extractions in these patients. A combination of local hemostatic agents are used to achieve hemostasis. Wagner et $\mathrm{al}^{26}$ presented an overall activity ranking of the materials used: Collagen $>$ gelatin $>$ oxidized regenerated cellulose. ${ }^{26}$

The current literature reports successful treatment protocols to prevent bleeding complications following oral surgery procedures. Management of patients with coagulation factor deficiency who require dental extraction or any other complex procedure is summarized as follows: In patients with mild hemophilia A before extraction/nerve block, Desmopressin $0.3 \mu \mathrm{g} / \mathrm{kg}$ (maximum dose $20 \mu \mathrm{g}$ ) intravenously over 20 to 30 minutes or subcutaneously should be given. ${ }^{20}$ Postextraction antifibrinolytic agents (e.g., tranexamic acid, $25 \mathrm{mg} / \mathrm{kg}$ t.i.d.) for 3 to 5 days should be given. Patient is advised to take soft diet for 7 days. In patients with moderate to severe 
hemophilia A before extraction, recombinant factor VIII concentrate 20 to $25 \mathrm{IU} / \mathrm{kg}$ can be given. ${ }^{5}$ Patients should be re-evaluated post procedure. In patients with hemophilia B (mild, moderate, severe) before extraction, recombinant factor IX concentrate 40 to $60 \mathrm{IU} / \mathrm{kg}$ should be given. Reevaluate patient post procedure. ${ }^{5}$

Various other preventive measures should be taken to prevent dental problems. Patients must be taught about the importance of regular cleaning (tooth brushing) with proper technique. The use of plaque disclosing tablets in the clinic is of value, as they will show the areas that are not being cleaned properly. The patient and their caretakers should be advised to restrict the intake of sugary foods and drinks at mealtime. Regular dental checkup should be done, which will allow early diagnosis and prompt treatment of dental problems. A routine scaling and polishing, including the use of ultrasonic scalers, is unlikely to cause significant bleeding. If the gingival condition is poor and there is a worry about bleeding, a 5-day course of metronidazole (200 mg 3 times a day), along with a chlorhexidine mouthwash can be used twice a day. ${ }^{20}$ This will decrease inflammation and the possibility of bleeding.

Removable prosthodontics are unlikely to cause any problems in patients with inhibitors. Similarly, fixed and removable orthodontic appliances may be used along with regular prevention and hygiene therapy. Restorations, crowns and bridges can safely be performed following local anesthetic injection guidelines. ${ }^{20}$

\section{Complications}

\section{Uncontrolled Bleeding following a Dental Extraction}

Early bleeds: In cases of recurrent bleeding following dental extraction within 24 hours of extraction, the splint should be removed and the area inspected to ensure that there are no mucosal tears. If there is mucosal damage, it should be sutured to prevent further problems. If the bleeding appears to be from the socket, it may be necessary to remove the blood clot and fibrin plug, irrigate the socket, and examine the area to ensure that there are no foreign bodies causing the problem. The socket should be packed and the splint should be fitted. Oral antibiotics should be prescribed if any foreign body has been located, as there may be some remaining infection.

Late bleeds: These usually occur between 2 and 5 days after the extraction and are commonly thought to be due to infection, although there is no evidence available in the recent literature to support this theory. If the bleeding is from the socket, the clot should be removed and the socket irrigated and repacked ${ }^{5}$ as earlier. The splint should be replaced and left in situ for at least 2 days. Oral antibiotics should be prescribed.

\section{Infection}

Minimal facial swelling: Dental infection causing minimal facial swelling can often be treated first with high-dose antibiotics, usually given intravenously. The patient should be monitored and if the swelling worsens, surgical intervention may be required. The cause of the infection, usually a decayed tooth, needs to be removed as soon as possible using the local measures previously described.

Marked facial swelling: Dental sepsis, which causes significant facial swelling, can become life-threatening. The patient should be treated with IV antibiotics and, if there is any risk of airway compromise, urgent surgical drainage should be performed. The patient should be closely monitored. In severely affected hemophilia patients, treatment planning should be done in consultation with the hematologist in a hospital setting. ${ }^{7}$

\section{CONCLUSION}

Prior to any dental procedure the patient should be referred to a hematologist to obtain a complete blood picture and to rule out deficient clotting factors, vitamin $\mathrm{K}$ deficiencies, and their plasma concentrations. ${ }^{26}$ Surgical treatment, including a simple dental extraction, requires meticulous planning with adequate execution to minimize the risk of bleeding, excessive bruising, or hematoma formation. All treatment plans must be discussed with the hemophilia unit if they involve the use of prophylactic cover. After dental procedures, blood loss of all kinds can be controlled locally with direct pressure or periodontal dressings with or without topical antifibrinolytic agents. ${ }^{10,29}$

\section{ACKNOWLEDGMENT}

Authors would like to thank the internal medicine staff, RajaRajeswari Medical College and Hospital, Bengaluru, Karnataka, India.

\section{REFERENCES}

1. Gómes-Moreno G, Cutando-Soriano A, Arana C, Scully C. Hereditary blood coagulation disorders: management and dental treatment. J Dent Res 2005 Nov;84(11):978-985.

2. Hockin MF, Jones KC, Everse SJ, Mann KG. A model for the stoichiometric regulation of blood coagulation. J Biol Chem 2002 May;277(21):18322-18333.

3. Brewer AK, Roebuck EM, Donachie M, Hazard A, Gordon K, Fung D, Clarkson J. The dental management of adult patients with haemophilia and other congenital bleeding disorders. Haemophilia 2003 Nov;9(6):673-677.

4. Kashyap R, Choudhry VP. Haemophilia. Ind Pediat 2000; 37:45-53.

5. Israels S, Schwetz N, Boyar R, McNicol A. Bleeding disorders: characterization, dental considerations and management. J Can Dent Assoc 2006 Nov;72(9):827. 
6. Stubbs M, Lloyd J. A protocol for the dental management of von Willebrand's disease, Hemophilia A and Hemophilia B. Aust Dent J 2001 Mar;46(1):37-40.

7. Peisker A, Raschke GF, Schultze-Mosgau S. Management of dental extraction in patients with Hemophilia A and B: a report of 58 extractions. Med Oral Patol Oral Cir Bucal 2014 Jan;19(1):e55-e60.

8. Björkman S, Berntorp E. Pharmacokinetics of coagulation factors: clinical relevance for patients with hemophilia. Clin Pharmacokinet 2001;40(11):815-832.

9. Poon MC, Lillicrap D, Hensman C, Card R, Scully MF. Recombinant FIX recovery and inhibitor safety: a Canadian post-licensure surveillance study. Thromb Hemost 2002 Mar;87(3):431-435.

10. Srivastava A, Brewer AK, Mauser-Bunschoten EP, Key NS, Kitchen S, Llinas A, Ludlam CA, Mahlangu JN, Mulder K, Poon MC, et al. Guidelines for the management of hemophilia. Hemophilia 2013 Jan;19(1):e1-e47.

11. Sultan Y. Prevalence of inhibitors in a population of 3435 hemophilia patients in France. Thromb Haemost 1992 Jun;67(6):600-602.

12. Hay CR, Ludlam CA, Colvin BT, Hill FG, Preston FE, Wasseem N, Bagnall R, Peake IR, Berntorp E, Mauser Bunschoten EP, et al. Factor VIII inhibitors in mild and moderate severity haemophilia A. UK Haemophilia Centre Directors Organisation. Thromb Haemost 1998 Apr;79(4):762-766.

13. Schwaab R, Brackmann HH, Meyer C, Seehafer J, Kirchgesser M, Haack A, Olek K, Tuddenham EG, Oldenburg J. Haemophilia A: mutation type determines risk of inhibitor formation. Thromb Haemost 1995 Dec;74(6): 1402-1406.

14. Addiego J, Kasper C, Abildgaard C, Hilgartner M, Lusher J, Glader B, Aledort L. Frequency of inhibitor development in haemophiliacs treated with low-purity factor VIII. Lancet 1993 Aug;342(8869):462-464.

15. Hay CR, Ollier W, Pepper L, Cumming A, Keeney S, Goodeve AC, Colvin BT, Hill FG, Preston FE, Peake IR. HLA class II profile: a weak determinant of factor VIII inhibitor development in severe hemophilia A. Thromb Haemost 1997 Feb;77(2):234-237.

16. Oldenburg J, Picard JK, Schwaab R, Brackmann HH, Tuddenham EG, Simpson E. HLA genotype of patients with severe hemophilia A due to intron 22 inversion with and without inhibitors to factor VIII. Thromb Haemost 1997 Feb;77(2):238-242.

17. O'Connell N, Mc Mahon C, Smith J, Khair K, Hann I, Liesner R, Smith OP. Recombinant factor VIIa in the management of surgery and acute bleeding episodes in children with hemophilia and high responding inhibitors. Br J Haematol 2002 Mar;116(3):632-635.

18. Mannucci PM. Desmopressin (DDAVP) in the treatment of bleeding disorders: the first 20 years. Blood 1997 Oct;90(7): 2515-2521.

19. Castaman G. Desmopressin for the treatment of haemophilia. Haemophilia. 2008;14(Suppl 1):15-20.

20. Gupta A, Epstein JB, Cabay RJ. Bleeding disorders of importance in dental care and related patient management. J Can Dent Assoc 2007 Feb;73(1):77-83.

21. Suwannaraks $M$, Sri-Udompom N, Isarangkura $P$, Chuansumrit A, Chaichareon P. The use of locally prepared fibrin glue in dental extractions of patients with bleeding disorders. Haemophilia 1998;4(3):302.

22. Boyar R, Schwetz J, Johnston J. Dental surgical management of hemophilia patients with inhibitors. Haemophilia 1998; 4:305.

23. Frachon $X$, Pommereuil $M$, Berthier AM, Lejeune $S$, Hourdin-Eude S, Quéro J, Mézière X, De Mello G, Garnier J. Management options for dental extraction in hemophiliacs: a study of 55 extractions (2000-2002). Oral Surg Oral Med Oral Pathol Oral Radiol Endod 2005 Mar;99(3):270-275.

24. Noor N, Maxood A, Mumtaz R. Dental management of haemophilic pediatric patients. Pak Oral Dent J 2012 Jun;32(1): 66-70.

25. Anderson JA, Brewer A, Creagh D, Hook S, Mainwaring J, McKernan A, Yee TT, Yeung CA. Guidance on the dental management of patients with haemophilia and congenital bleeding disorders. Br Dent J 2013 Nov;215(10):497-504.

26. Wagner WR, Pachence JM, Ristich J, Johnson PC. Comparative in vitro analysis of topical hemostatic agents. J Surg Res 1996 Dec;66(2):100-108.

27. Rayen R, Hariharan VS, Elavazhagan N, Kamalendran N, Varadarajan R. Dental management of hemophiliac child under general anesthesia. J Indian Soc Pedod Prev Dent 2011 Jan-Mar;29(1):74-79.

28. Al-Belasy FA, Amer MZ. Hemostatic effect of n-butyl-2cyanoacrylate (histoacryl) glue in warfarin-treated patients undergoing oral surgery. J Oral Maxillofac Surg 2003 Dec;61(12):1405-1409.

29. Franchini M, Rossetti G, Tagliaferri A, Pattacini C, Pozzoli D, Lorenz C, Del Dot L, Ugolotti G, Dell'aringa C, Gandini G. Dental procedures in adult patients with hereditary bleeding disorders: 10 years experience in three Italian Hemophilia Centers. Haemophilia 2005 Sep;11(5):504-509. 